\title{
A Review of Floating Semisubmersible Hull Systems: Column Stabilized Unit
}

\author{
Agbomerie Charles Odijie ${ }^{1}$, Facheng Wang $^{2}$, Jianqiao $\mathrm{Ye}^{3, *}$ \\ ${ }^{1}$ Continental, ContiTech Industrial Fluid System, Dunlop Oil and Marine Limited, Grimsby, UK \\ ${ }^{2}$ COTEC Offshore Engineering Solutions, Beijing, China \\ ${ }^{3}$ Department of Engineering, Lancaster University, Lancaster, UK
}

\begin{abstract}
Column stabilized semisubmersible is one of the most commonly used hull systems for the design and development of drilling and production platforms used for offshore deep water operations. Recent reconfiguration and design alterations have improved its hydrodynamic behaviour in rough weather conditions and, thus, its application and functionality in ocean engineering. Semisubmersible dry-trees applications and large wind turbine foundation systems in ultra-deep waters require high payload integration for reduced motion responses in all degrees of freedom. This paper presents a review of recent industrial and academic contributions to the development of column stabilized semisubmersible hulls used for deep water operations. It also provides an overview of the motion and structural attachments of semisubmersibles. The type and formation of dry-trees semisubmersibles are discussed. The dynamic behaviour and comparative advantages of them are also explained.
\end{abstract}

Keywords: Deep-draft semisubmersible, dry-tree semisubmersible, paired column semisubmersible, vortex induced vibration

\begin{tabular}{l|l}
$\begin{array}{l}\text { Abbreviations } \\
\text { PC-Semi }\end{array}$ & Paired Column Semisubmersible \\
HVS & Heave Vortex Supressed \\
CFD & Computational Fluid Dynamics \\
DD-Semi & Deep Draft Semisubmersible \\
RAO & Respond Amplitude Operator \\
VIM & Vortex Induced Movement \\
VIV & Vortex Induced Vibration \\
DOF & Degree of Freedom \\
VLFS & Very Large Floating Structure \\
API & American Petroleum Institute \\
DNV & Det Norske Veritas \\
GOM & Gulf of Mexico \\
TTR & Top Tension Riser \\
TLP & Tension Leg Platform \\
DTS & Dry-Tree Semisubmersible \\
BOP & Blowout Preventer \\
MARIN & Marine Research Institute of the Netherland \\
\hline
\end{tabular}

\subsection{Introduction}

Over the years the demand for fossil fuel products have increased significantly, which has expanded the search for crude deposit to remote sea areas where the weather/sea conditions are not favourable for conventional oil platforms (Lloyd's, 2011). The production capacity of oil reserves situated in these areas of the sea is usually prolific, making them targets for oil companies. Because of the high consumption rate of these products, there is a constant search for resources to keep the prices affordable. The basic challenge in exploring (drilling and production) reserves situated in such areas is how to design a structure that can meet with safety standards set by 
regulatory bodies. Floating platforms have been harnessed over the years for this purpose. As a result, the demand for floating offshore structures has gradually increased in the oil and gas industry. The nature of the weather conditions (wave, current, and wind) requires high-safety standards for structures designed to operate in them. Apart from exploration purpose, there are other applications of floating platforms such as offshore crane systems and support structures (Erdbrink, 1990). Generally, in the oil and gas industry, floating platforms are mainly used in situations where it is not possible to use a fixed structure that is jacket, jack-up or gravity based. Priest (2007) reviewed the evolution of floating structures from the conventional compliant tower. Compared with the traditional fixed/rigid structures, the floating/flexible state of the submersibles tends to attract much less forces. Concerning fatigue analysis of floating structures, some researchers concluded that because of their low stiffness, they are more likely to make sea working conditions safer. There are different factors that affect the functionality of floating structures, including payload integration, motion characteristics, sea depth, stability criteria and size. Of all these factors, sea depth is the most influential factor that affects recent designs of the hull form. The oil and gas industry has a huge task in offsetting the depth challenges associated with oil reserves situated in very deep regions of the ocean (Alexei, 2001; Bentley and Koci, 2007; Makinson et al., 2016). Some of the challenges include well design, unique drilling and production operations, design of structure and regulatory policies. As a result, the industry has gradually developed more sophisticated procedures and equipment to cope with the challenges. This development has been focused more on column stabilized semisubmersible units, because of the multiplicity of advantages they offer. In the following sections, we will review some of the significant design contributions that have rapidly proliferated its usage in ocean engineering. A review of design optimizations of semisubmersible column stabilized units in the oil and gas industry is included. The review also focuses on the studies describing the dynamics, strength, and applications of semisubmersible hulls. Emphasis is laid on the recently postulated dry-trees and Heave Vortex Suppressed (HVS) semisubmersible concepts.

\subsection{Background of Semisubmersible Hull}

The development and design of semisubmersible hulls can be traced back to the early 1960s when there was a rapid need to increase the stability of floating systems. Bruce Collipp was credited in (Leffler, Pattarozzi and Sterling, 2003) for designing the first semisubmersible platform. His early design and development of this structure were inspired from the stability obtained by partially submerging a floating structure to avoid capsizing in rough sea conditions. He called his first design the Bluewater-1. Since then the use of semisubmersible hull systems in the oil and gas industry has grown tremendously. It has been used for designing mobile drilling units, floating production systems, barges, crane systems, support vessels, transportation vessels and many other applications. Although it has different forms, the column stabilized form is generally accepted to be the most effective design for drilling purpose, which was later adopted for production. This platform consists of a top-deck section, columns and a pontoon. Originally, the buoyancy was provided by the pontoon, which helps to keep the structure floating. The buoyancy of the recent semisubmersibles is provided by the amount of submerged draft which includes both the pontoon and the columns. Like all floating structures, semisubmersibles have six degrees of freedom and are flexible in all directions. These movements cause fatigue on the risers, mooring lines and other structural attachments and, therefore, they need to be controlled in both normal and harsh sea conditions. Over the years, the use of semisubmersible hull systems has been extended to deep waters; from the first one (Bluewater 1) to the modern semisubmersibles designed by Petrobras, Technip, Shell, Chevron, Transocean, Total, Maesrk, Aker Solutions and many others.

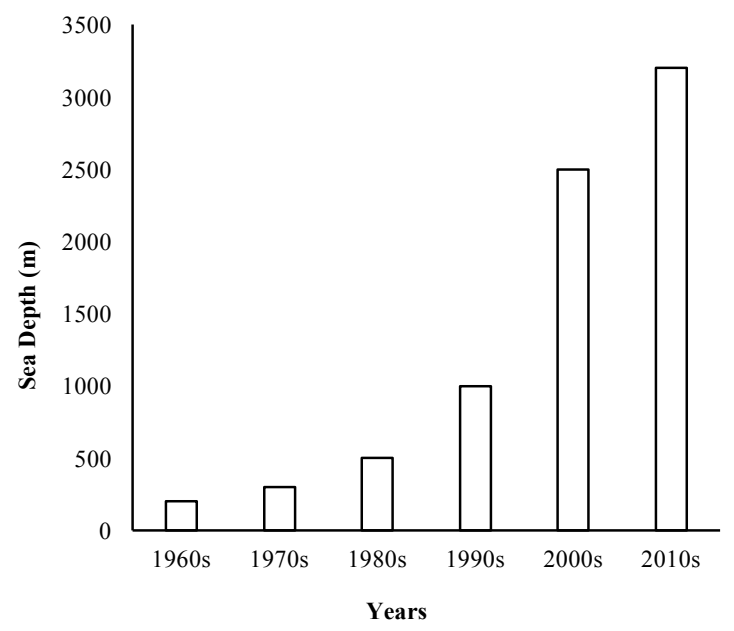

Figure 1 Sea depth growth of semisubmersible hulls from 1960s-2010s

*Correspondence author (j.ye2@lancaster.ac.uk) 
Figure 1 shows a progressive growth in the application of semisubmersible hulls over the last 50 years. The conceptualization and designs that triggered this growth were carried out by researchers from both academic and industrial environment, which has helped to improve the performance and functionalities in ocean engineering. These investigations were mainly done to understand the response and strength of the hulls under different environmental loading conditions.

\subsection{The Evolution of Design}

In the early 1980s, (Akagi and Ito, 1984) presented a motion optimized design of the conventional semisubmersible platform used in the 1970s. These conventional semisubmersibles (example: Argy II FPU and Buchan A) were characterized with much higher motion response than what we have now, because of the amount of steel present in their cut-water plane area (more inline columns and braces). Their design was focused on reducing the natural frequencies of the hull on its vertical plane to prevent lock-in phenomenon due to resonance with the wave oscillating frequencies in the heave DOF. To achieve this, they increased the displaced volume of the semisubmersible, and reduced its cut-water plane area. Six circular columns arranged in-line (three on each side) were designed alongside two large circular pontoon sections (see Table 1). The pontoon size guaranteed a high displaced volume, while the small diameter of the columns maintained a small area in the water plane. The mathematical formulation of this relates the water-plane stiffness, added mass and natural frequency of the hull. Considering the wave frequency conditions, the technicality involved was how to determine the displaced volume and the accurate dimension of the columns that could satisfy the frequency requirement. This was a revolutionary idea that increased the application of semisubmersible hulls in the oil and gas industry, because a great reduction in the motions on the vertical plane of a traditional semisubmersible was achieved. This method has been also implemented in some boat and vessel designs to increase their stability (Knox, et al, 2015).

In the late 1990s, (William, et al, 2001) made a series of presentations on some of their findings from the experimental tests carried out on different shapes and sizes of semisubmersible platforms. They tested on how to increase the stability of semisubmersibles during rough sea conditions. There was an urgent need for this from the commercial operators in deep sea who reported high level of instability for tidal conditions due to the increase in water level because of global warming. At the end of their work, they built a three-column semisubmersible system using the basic principle for stability of floating bodies. i.e.; by designing a system having its centre of gravity below the centre of buoyancy (see Figure 2). Hence, they increased the length of the submerged part of the hull to keep the weight centre further below the water plane, and called it deep-draft semisubmersible (see Table 1). A patent of this design was issued in 2001 (William, et al, 2001). This was another turning point in the development of modern offshore floating systems, i.e., semisubmersibles. The design and development of the MinDOC3 semisubmersible was attributed to this idea (American Bureau of Shipping, 2015). The idea was also applied in spar platform, keeping the hard tank at the very bottom of the hull. Increase in the total draft size often leads to total increase in the length of the structure, therefore, making it behave as a slender body. The major problem encountered by a slender body under wave and current loads is vortex induced vibration (VIV), sometimes called vortex induced movement (VIM), when the time it takes for the structure to respond in a complete cycle is longer than 21 seconds or more. This is mostly the case for large floating bodies.

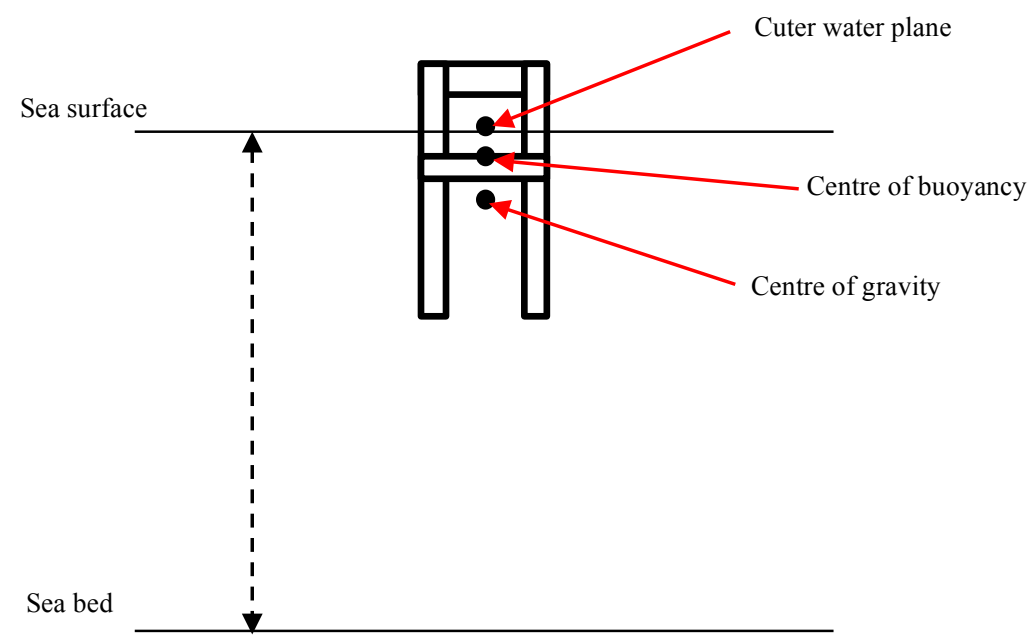

Figure 2. Illustration of a deep draft semisubmersible 
The nature of the draft also requires structural attachments (risers and moorings) to be configured in a certain way to suit its application as recorded in (Bindingsbo and Bjorset, 2002; Rijken, et al, 2011). The length of the draft also makes them behave as slender bodies, and this can be a massive disadvantage in high sea current situations. When fluid flows through a blurred body, a stream of vortexes are formed on the wake of the disturbance. These vortexes oscillate at a particular frequency called the vortex shedding frequency $f_{v}$. When the vortex shedding frequency is equal or close to the natural frequency of the structure, a resonant phenomenon occurs and the structure starts to move in an excessive vibratory manner. This is the movement known as vortex induced movement or vortex induced vibration (VIV). VIV is a major problem that is observed in most offshore slender bodies such as risers, mooring lines, etc. The evolution of deep draft semisubmersibles has added to that list. Different researchers have made conscious attempts to investigate the effect of this phenomenon on deepdraft semisubmersibles. Hong et al. (2008), Gonçalves et al. (2012a), Gonçalves et al. (2012b), Gonçalves et al. (2012c) and Bai et al. (2013) are some of the recoded reports (experimental and numerical methods) on how a deep draft semisubmersible responds to shed vortexes. The extent of this effect was greatly influenced by the inline motions (surge motions) induced by the hydrodynamic wave loadings (Gonçalves et al., 2012b). Deep draft semisubmersibles (DD-Semi) have different forms. (Halkyard, 2005; Zhu, et al., 2012) explained the concept of a DD-Semi with moveable heave plates. This is an imitation of the truss spar design. The inclusion of the heave plates results in a massive reduction in vertical/heave response of the structure, making it suitable for ultra-deep well operation. Other forms of DD-semi include paired column semi and conventional four columns DD-Semi (e.g. Petrobras 55). Irrespective of the numerous advantages associated with the deep-draft semisubmersible concept, there are several challenges associated with them. The issue of vortex shedding phenomenon resulting in destructive oscillating amplitude is of key interest, and operators of this type of structures employed strakes and other vortex suppressing devices in circumventing the effect. A significant disadvantage of deep-draft semisubmersibles is their limited range of applications, as the recommended standard for most regulatory bodies only permit 5 percent offset of draft for operating conditions and 7 percent or less for damage condition. As a result, hull formations such as a PC-Semi with a draft size of over $50 \mathrm{~m}$ are restricted to regions with a sea depth of over $2000 \mathrm{~m}$. Deep draft semisubmersible hull systems are mainly used for designing drilling and production units in the oil and gas industry and the recently developed paired column semisubmersible platforms for dry trees use have been added to the fleet. In 2010, Xu (2011) carried out CFD simulations on different semisubmersible hull types to investigate their VIM responses. From these simulations, it was discovered that any form of alteration on the reciprocating vortexes shed from an arrangement of columns would reduce its amplitude of oscillation. That is, the oscillating vortexes shed from columns with two different diameters are likely to have smaller amplitude when compared to if they had the same diameter. The authors also compared the RAO (Response Amplitude Operator) plots for both cases, and recorded favourable wave forces, moments and motions from the novel semisubmersible configuration. The new design concept reduced the size of the pontoon section and added additional material to the base of the columns proportionately, keeping the same displaced volume (See Table 1). $\mathrm{Xu}$ (2011) explained the formation and presented the model test results from the tests carried out from this hull model. Its comparative advantages in lowering the centre of gravity of deep draft semis (William, Bennett and Laborde, 2001) were explained, alongside with advantages in the reduction of the rotational motions (roll and pitch) in the horizontal plane. This hull has been named the future of deep-draft semisubmersibles because of these advantages. Recently, Diamond Offshore Drilling and other design companies have been optimizing their old semisubmersibles to meet the contemporary challenges associated with deep water operations. This method has been very effective in achieving that goal. The recent reconstruction of Ocean Apex and Ocean Onyx is a good example of the application of Xu's method in optimizing semisubmersibles for deep water operations (Diamond Offshore, 2016). The three columns semisubmersible hull concept postulated for the deep draft by William, et al, (2001) was later developed into a semisubmersible vessel that can function as a foundation system (see Table 1). This method was not very successful in the oil and gas industry because it offered less displacement. Malcolm and Dixon (2001) presented a representation of this concept in a column-stabilized form. This concept has been greatly harnessed in the development of large wind turbine foundation systems because of the stability offered by the three legged structured components. Despite the advantages offered by this hull concept, Sharma et al. (2010) clearly stated that low deck space was a significant disadvantage of the three-column semisubmersible hull. Another important contribution to the development of semisubmersibles is the introduction of the truss pontoon semisubmersibles. The concept has received very significant attention in the oil and gas industry, but has not been able to advance to construction stage. Some work on truss pontoon semisubmersibles can be found in Srinivasan (2004), Chakrabarti et al. (2007), Ding and Soester (2011) and Sundaravadivelu, et al (2014). The work presented by Chakrabarti et al. (2007) explained the fundamental effects of response performance of the hull by adding the truss section that contains heave plates. They recorded significant improvement in the heave and pitch motions, which was attributed to the added mass in the heave DOF offered by the heave plates. They compared the results from diffraction method, Morison equation and their test setup, and recorded reasonable agreements in their findings.

*Correspondence author (j.ye2@lancaster.ac.uk) 
Table 1 Contributions to the development of modern semisubmersible hull

\begin{tabular}{|l|l|l|l|l|l|}
\hline Author (s) & $\begin{array}{c}\text { Akagi and Ito } \\
\text { (1984) }\end{array}$ & $\begin{array}{c}\text { William, } \\
\text { Bennett and } \\
\text { Laborde (2001) }\end{array}$ & \multicolumn{1}{|c|}{ Xu (2011) } & $\begin{array}{l}\text { Malcolm and } \\
\text { Dixon (2001) }\end{array}$ & $\begin{array}{c}\text { Ding and } \\
\text { Soester (2011) }\end{array}$ \\
\hline Function (s) & $\begin{array}{l}\text { Reduction in } \\
\text { cut-water plane } \\
\text { area, to reduce } \\
\text { the hydrostatic } \\
\text { stiffness. }\end{array}$ & $\begin{array}{l}\text { Redistributing } \\
\text { the hull weight; } \\
\text { concentrating } \\
\text { more weight } \\
\text { below the cut- } \\
\text { water plane to } \\
\text { keep the centre } \\
\text { of gravity below } \\
\text { the centre of } \\
\text { buoyancy, }\end{array}$ & $\begin{array}{l}\text { Heave and } \\
\text { vortex } \\
\text { suppressed } \\
\text { semisubmersible. } \\
\text { (HVS) }\end{array}$ & $\begin{array}{l}\text { Three column } \\
\text { semisubmersible }\end{array}$ & $\begin{array}{l}\text { Inclusions of } \\
\text { heave plates on } \\
\text { the pontoon } \\
\text { section to } \\
\text { increase it } \\
\text { added mass } \\
\text { and reduce } \\
\text { heave motions. }\end{array}$ \\
\hline
\end{tabular}

Table 1 shows some recent improvements on semisubmersible platforms reported by different researchers. Each of these novel concepts for semisubmersible hull designs has its comparative advantages as relating to the operational requirements in deep and ultra-deep sea. They also have their respective shortcomings, which make it impossible to have a single standard hull concept for all semisubmersible applications. One unique characteristics of these semisubmersible hull forms is that at the time each of them was conceptualized, they were all designed to function at a greater sea depth than the existing ones, which is usually the trend in the offshore industry. There are other contributions that have been developed to increase the functionality of these hull systems, such as the centralized pontoon system, plate-like pontoon, rectangular column formation, etc. In this paper, however, we have restricted our discussion to the most significant contributions.

\subsection{Degree of Freedom}

Semisubmersibles are floating hulls, which are, therefore, flexible bodies and free to move. This dynamic behaviour is of primary interest during their design stage. Wilson (1984) explained the six different directions (degrees of freedom) in which a floating structure (ships, barges, boats or platforms) responds when environmental or operating loadings are placed on them. The translational response in the $\mathrm{X}, \mathrm{Y} \& \mathrm{Z}$ co-ordinate directions are called surge, sway and heave, while the rotational response about these axes are called, respectively, roll, pitch and yaw. These six degrees of freedom take place on two planes, i.e., the vertical and the horizontal plane, as shown in Table 2. The water surface is on the XY plane, and $\mathrm{X}$ is the direction of flow. The $\mathrm{Z}$ direction is normal to the XY plane. It is important to understand the relationship between the six degrees of freedom and the planes they operate. The nature of the hydrostatic behaviour of semisubmersibles (and most floating bodies) is relative to these planes.

Table 2 Degrees of freedom of a floating body

\begin{tabular}{l|l|l}
\hline Direction & Translational & Rotational \\
\hline $\mathrm{X}$ & Surge & Roll \\
$\mathrm{Y}$ & Sway & Pitch \\
$\mathrm{Z}$ & Heave & Yaw \\
\hline
\end{tabular}

The motions are usually denoted as $\mathrm{U}_{\mathrm{x}}, \mathrm{U}_{\mathrm{y}}, \mathrm{U}_{\mathrm{z}}$, ROTX, ROTY, and ROTZ, where $\mathrm{U}_{\mathrm{x}}, \mathrm{U}_{\mathrm{y}}$, and $\mathrm{U}_{\mathrm{z}}$ are the movements in the $\mathrm{X}, \mathrm{Y}$ and $\mathrm{Z}$ directions, respectively; ROTX, ROTY, and ROTZ are the respective rotations about the $\mathrm{X}, \mathrm{Y}$ and $\mathrm{Z}$ axes.

\subsection{Structural Attachments}

Floating platforms do not exist as single units as they are designed for a wide range of applications, and semisubmersibles are not an exception. For example, drilling and production require risers, crane system requires anchors, positioning require moorings, and so on. There are various structural attachments to floating structures, while we only discuss the two main attachments in this study, i.e., mooring lines and risers.

\subsubsection{Mooring Lines}


Mooring lines and tethers are used to keep a floating platform in place, as illustrated in Figure 3. They act as the foundation (flexible) system, and are connected from the base of the submerged part of the hull to the seabed. Mooring lines are basically applied in different forms, depending on the extent of response the floating structure can have. For deep draft semisubmersibles, there are two conventional types of mooring applications; taut mooring and centenary or slack mooring. The responses of a floating structure are therefore directly affected by the stability, stiffness, fatigue, and life cycle of the moorings. Researchers have carried out investigations to analyse the extent of these influences. In a conventional practice, mooring designs were done alongside with hull design, considering recommended standards (API, DNV) as the benchmark. There is no generally acceptable design system for mooring lines, as each hull is designed to meet the environmental and operational loading conditions for the particular task it is expected to perform. Mavrakos et al. (1996) studied the dynamics of deep water mooring systems. They presented comparisons between numerical analysis and experimental investigations on the force response of mooring lines attached to a floating buoy. Sarkar and Taylor (2001) proposed a technique for analysing the dynamics of mooring cables and its boundary excitations. Researchers have demonstrated that an increase in the damping of mooring lines helps to reduce surge and pitch motions of spar platforms operating in deep waters. It is important to mention that the conventional way of altering the damping factor of mooring lines is in its material selection. Jordan and Beltran-Aguedo (2004) studied the nonlinear behaviour of moorings, generating some correlations that described the behaviour of moorings in viscous environments. Apart from the challenges associated with the dynamic positioning of a mooring line, the way to join it to the seabed and the structure was also a problem. The coupling effect of mooring lines and offshore platforms is a fundamental area of study in the oil and gas industry. Its dynamic complexity varies along the entire mooring chain; from the seabed pegs, to the contact point on the platform. Recently, suction cans have been employed to circumvent the effect of this challenge. This technique was used to anchor the mooring lines of the Perdido Spar (world biggest spar platform) to the seabed in Gulf of Mexico (GOM), replacing the conventional concrete piles. This technique has improved safety and life span of the lines with reduced maintenance cost.

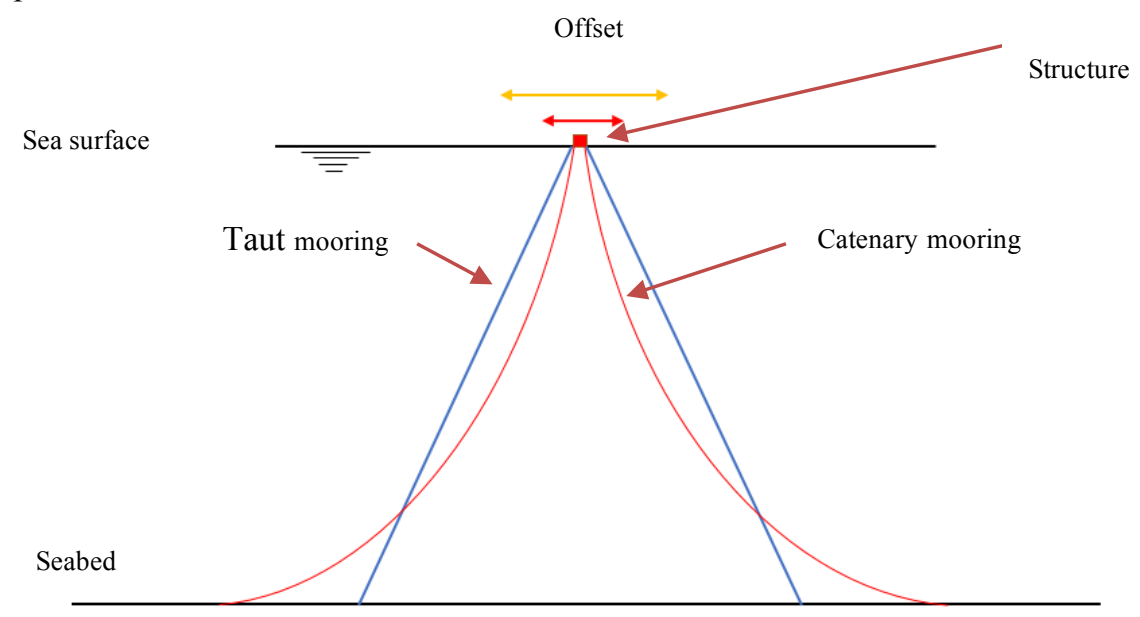

Figure 3. Illustration of a typical mooring system

Recently, a non-uniform mooring configuration (material selection) has been adopted in the industry because of the high stiffness they offer. Steel-polyester-steel is the most commonly used configuration. The short steel chains are connected to the anchors and the fairleads, while a significant part of the line is made from polyester rope.

\subsubsection{Risers}

Risers are pipeline structures used to transport fluid in and out of the well. They come in different sizes, shapes and materials. Chakrabarti (2005) showed the types, usage and dynamics of drilling and production risers. Because risers are directly connected to wellheads or Blowout Preventers (BOPs), which are in direct contact with the seabed, not only they are affected by the structural response of the platform and ocean waves, but also they respond to seismic and earthquake conditions (Duan et al., 2010). The design of risers and subsea pipe structures is recorded in Bai and Bai (2005). The nonlinear behaviour of risers under vibratory motion was investigated by Kaewunruen et al. (2005), where it was concluded from the experimental and numerical analyses that increasing the speed of the fluid carried by risers reduced their natural frequencies. A major challenge faced by risers in the offshore industry is vortex induced vibration, which is a result of the vortexes formed when fluid passes through them. Because this effect is not directly caused by the floating structure, it is of less interest in this research.

\section{Dynamics}

*Correspondence author (j.ye2@lancaster.ac.uk) 
Semisubmersible hulls are classified as Very Large Floating Structure (VLFS). Their applications are restricted almost exclusively in the oil and gas industry, and thus are exposed to extreme weather conditions. As a result, different researchers have tried to remodel this structure to reduce the effect of sea waves and optimize their dynamic behaviour. Modern column stabilized semisubmersibles are designed with small cut-water plane area. This means less area is exposed to wave loads and less motion is generated in the vertical plane, including heave roll and pitch. The sectional hydrodynamic force $\left(F_{d}\right)$ of a semisubmersible is calculated using the conventional methods as shown in Equations 1 and 2. Morison's equation and 3D diffraction method are generally the acceptable way to determine the nature of hydrodynamic loadings on a floating body. Recommended standards also require the use of developed experimental models (tow test). However, these tests are normally scaled down, and cannot represent the actual loading scenarios of these structures.

$$
\begin{aligned}
& F_{d}=\rho C_{m} A \dot{u}+\frac{1}{2} \rho C_{D} D|u| u \\
& F_{d}=\frac{1}{2} \rho C_{D} D|u| u-\frac{1}{2} \rho C_{d m p} D|\dot{x}| \dot{x}-\rho A \dot{u} C_{m}+\rho A \ddot{x}\left(1+C_{m}\right)
\end{aligned}
$$

Where,

$\rho=$ Density of sea water

$C_{D}=$ Drag coefficient

$D=$ Diameter of the structure

$u=$ Velocity of fluid particle

$\dot{u}=$ Fluid acceleration

$C_{d m p}=$ Damping coefficient

$\dot{x}=$ Velocity of structure

$C_{m}=$ Inertia coefficient of the structure

$\ddot{x}=$ Acceleration of the structure

For a hull in motion under wave and current interactions, the hydrodynamics force is represented as the summation of the forces from the drag, the hydrodynamic damping, added mass and fluid acceleration (as presented in Equation 2.

The calculation of the parameters presented in Equation (2) is complex due to the unsteady behaviour of ocean conditions. Researchers have employed numerical and experimental means to calculate them. Williams et al. (2011) calculated the effect of wave loadings on a typical semisubmersible platform, where a computer program was developed to calculate the wave loadings and finite element method was used to analyse the deformation of the structural members. The strength of the structure was tested by investigating the response at different flow incidence angles. A better knowledge of this can be found in the investigation that was carried out by Wu et al. (1997). In the former, a model test was conducted in extreme weather conditions, where the amplitudes of the surge and heave responses were recorded. The effect on the moorings (mooring force) was also established. The amplitude was plotted against the frequency of each DOF, considering the varying wave forces. The effect of the mooring line damping factor was also investigated, and it was concluded that the mooring damping only had significant effect on the translational responses in the horizontal plane (sway and surge) during low and moderate weather conditions, and little or negligible effect during extreme weather conditions.

The nature of the hydrodynamic motion of a hull is relative to a resonant phenomenon determined by the flow properties (wave frequencies, vortex shedding frequencies) and the natural frequency/oscillating period of the hull. Although the hull motion increases with increase in the wave amplitude, the maximum motions are generally recorded at the resonant frequencies. Semisubmersibles are therefore designed to operate with natural periods that are far away from the oscillating periods of the wave. For a simple illustration, the natural frequency of the hull is basically a function of its stiffness and mass properties as;

$$
\begin{aligned}
& \omega_{n}=\sqrt{\frac{K_{i}}{M+M_{a}}} \\
& T_{n}=\frac{1}{\omega_{n}}
\end{aligned}
$$

*Correspondence author (j.ye2@lancaster.ac.uk) 
Where,

$\begin{array}{ll}K_{i} & \text { The stiffness of the hull in } i \text { degree of freedom. } \\ M & \text { Mass of the hull; details will be discussed in subsequent chapters. } \\ M_{a} & \text { Added mass parameter } \\ T_{n} & \text { Natural period }\end{array}$

The wave parameters are recorded in weather buoys and recommended in documents such as American Petroleum Institute (1997). From ocean study, the operating range for 100-years and 1000-years wave periods for hurricane conditions falls between $1 \mathrm{~s}$ and 17.2s. Very high periods (close to $21 \mathrm{~s}$ ) have previously been recorded for tsunami cases, but this was not recorded in deep waters. As earlier cited, the natural periods of deep draft semisubmersibles in each DOF are therefore designed to operate outside this range. For example, Matos, et al. (2011) presented the parameters of Petrobras-52 deep draft semisubmersible hull, and recorded 23.7s, 33.0s, and $31.5 \mathrm{~s}$, respectively, as the natural oscillating periods of its heave, roll and pitch DOF. The prototype of Glomar Artic 3 semisubmersible presented in $\mathrm{Wu}$, et al. (1997) cited the natural heave period of the hull as $20.5 \mathrm{~s}$. Tan et al. (2016) presented a model of a heave and vortex supressed deep draft semisubmersible. The hull was designed with heave natural period of $19.1 \mathrm{~s}$, while $29.4 \mathrm{~s}$ and $29.3 \mathrm{~s}$ for the roll and pitch DOF, respectively. It also cited $18.4 \mathrm{~s}, 25.8 \mathrm{~s}$ and $25.8 \mathrm{~s}$ for the respective heave, roll and pitch natural period for conventional semisubmersibles in south East Asia. Hussain et al. (2009) presented the natural periods derived from a decay test of conventional deep draft semisubmersibles used in the GOM. The heave, roll and pitch natural periods were 20.0s, 28.4s, and $27.3 \mathrm{~s}$, respectively. The heave natural periods for different draft cases were between $21 \mathrm{~s}$ and $22 \mathrm{~s}$. Figure 4 shows a relationship between the maximum wave periods recorded from weather buoys, and the heave natural periods of recently developed semisubmersibles.

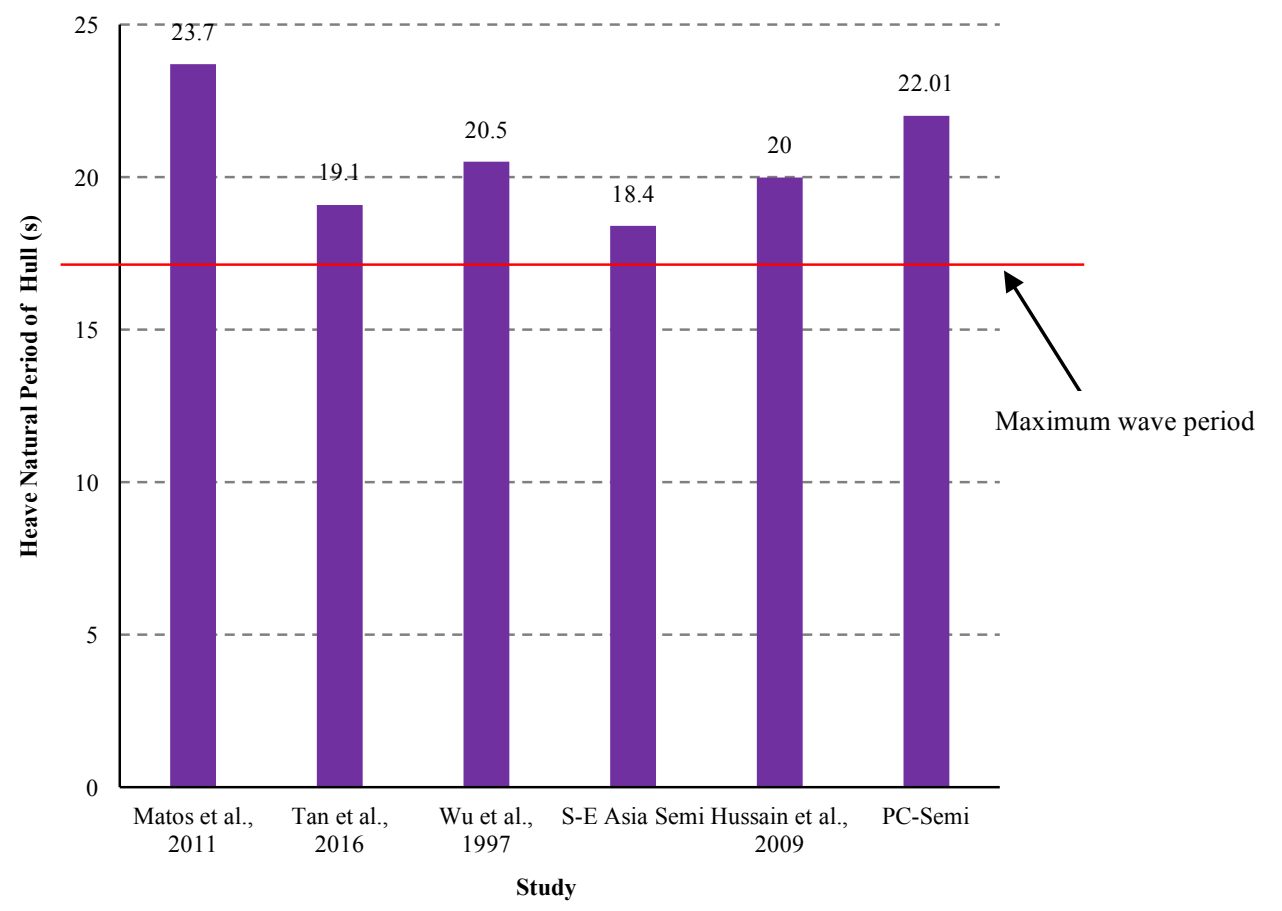

Figure 4. Heave natural periods of recent semisubmersible hull designs

The red line in Figure 4 indicates the maximum wave period presented in American Petroleum Institute (1997), which is $17.2 \mathrm{~m}$. It is important to mention that we have only compared the heave natural periods because all other periods are further away from the wave period due to their high added mass parameter during oscillation.

There are similarities between the studies recorded in Hussain et al. (2009) and Matos, et al. (2011), as they both show the nature of deep draft semisubmersibles used in the GOM over the last decade. The variation in their heave periods is due to the hull mass and the geometric parameters of the columns used. Matos et al. (2011) presented a study of P-52 semisubmersible operating in the GOM. The future recommended semisubmersible hull designs for improved motion behaviour are documented in Odijie et al. (2017), Odijie and Ye (2015) and Tan et al. (2016). 


\subsection{Strength}

The design of early semisubmersibles had issues with their strength estimation. It was complex to calculate the effect of wind and wave loads on the structural integrity of a hull. Over the last 30 to 40 years, sophisticated numerical and experimental techniques have been developed to calculate the strength of multiple column arrangements in deep waters. In this review, we discuss on the most conventional method in the modern time, i.e., Finite Element Analysis. Recently developed software packages make it possible to account for the weight distribution around a hull, operational and environmental loadings. This means that we can calculate the stresses at joints subjected to any load cases, select the type and grade of steel preferable for hull construction and resize/re-dimension any of the components to reduce the effect of the loads on them. Apart from the challenges associated with estimating the environmental loads, the weight distribution of a hull is also a fundamental property that affects the strength of the hull. The mean weight of a hull is estimated from the weight summation of columns, pontoons, and braces, as shown in Equation 5 .

$$
W_{\text {hull }}=W_{\text {Pontoon }}+W_{\text {columns }}+W_{\text {Braces }}
$$

Where $W_{\text {hull }}$ is the weight of the hull, $W_{\text {pontoon }}$ is the weight of the pontoon, $W_{\text {columns }}$ is the weight of the columns and $W_{\text {braces }}$ is the weight of the braces.

American Bureau of Shipping (2004), Det Norske Veritas $(2011,2012)$ and DNV GL (2015) discussed ways of classifying and estimating the level of allowable stresses and buckling instability of all offshore floating structures; including semisubmersibles. Design methods, such as the Load Resistance Factor Design (LRFD) and Working Stress Design (WSD), were recommended; depending on which is more appropriate for the loading conditions the structure is designed for. Det Norske Veritas (1987) and American Petroleum Institute (2008) presented a set of guidelines on how to estimate the plate geometric and mechanical parameters for hull (columns, braces, reinforcement) construction. For structural analysis, Det Norske Veritas (2011) recommend non-linear finite element modelling for all load cases including static cases, dynamic cases, transient phase during installations, operating case, survival cases, and damage cases.

During rough weather, a hull experiences bending and twisting (torsional behaviour) (Begnaud et al., 2002). There is a wide range of literature in the ship catalogue that explain this elastic behaviour. Newman (1994) studied the motions and deformation experienced in barges and columns under regular wave loading. This is possible due to the introduction of some basic assumptions that the flow is incompressible, inviscid, non-rotational and small amplitude. With these assumptions, mathematical models were generated to understand the bending and continuous deformation at different mode shapes of a free-free (both ends) submerge floating column and barge. For columns, high resonant deflection was noticed within the range of occurring wave energy. Comparisons for hinge joints and free conditions were analysed for a floating barge, and the effect of constraints were investigated for some degrees of freedom. Xu and Haddara (2001) further developed a method for estimating the wave induced bending moment on a ship from its motion characteristics. They developed a set of mathematical models describing the bending moment of a floating body and used a network of cellular computational structures (neutral network algorithm) to understand the bending tendencies of the bodies under wave loading. An experimental setup was also put together to validate the accuracy of their models, and significant conclusions were made on incorporating the models into hull response monitoring systems. Although future development of this technique has been proposed for monitoring reasons, this method does not provide structural design engineers with enough information on how to determine regions around the hull where steel reinforcement might be required. Kyoung et al. (2005) numerically investigated the impact load of sloshing on a cylinder using finite element method based on Hamilton's principle. They developed a flow domain around a circular cylinder, calculated it based on Einstein's notations, and carried out a time history analysis. Considering finer mesh grid around the column surface, it was concluded that increase in water depth was very likely to lead to a corresponding increase in wave impact load. Kashiwagi (2000) described the hydrodynamic nature of fluid interactions between a set of arranged columns supported by a large flexible structure (pontoon). With this numerical model, the motion equations of the topside integral part were solved by studying the effect of the trapped wave and flow circulation within the columns and the possible effects of elastic deflection of these on the topside. Any of these above-mentioned techniques can be used to evaluate the strength of the fifth-generation semisubmersibles.

\subsection{Application for Drilling and Production Units: Dry-Trees Concepts}

For oil and gas production, dry-trees technology is predominately used on Spar and Tension Leg Platform (TLP) because they offer reduced motion response in their vertical plane. Over the last decade, there has been an

*Correspondence author (j.ye2@lancaster.ac.uk) 
urgent need to reconfigure the existing semisubmersible floating hull platforms used in deep waters to suit newly developed regulatory policies, and also to improve its motion characteristics, in order to enable it adapt to newly discovered well depths and to reduce the cost of drilling and production operations (Offshore-Mag.,2012). This demand triggered the research and development of dry-trees semisubmersibles.

Dry trees systems are possible with the use of tensioners, such as Top-Tension-Risers (TTR). This type of risers is used for both drilling and production purposes. The top of the riser carries the tensioner, which is traditionally supported by the deck system of the hull (Figure 5). At the top (the main tensioner), it has multiple column system arranged at an angle to each other, moving with different stroke limits and controlling the fluid passage in and out of the riser. Its vertical nature exposes it to VIV phenomenon, which requires attention by design requirements. Some applications involve the inclusion of strakes to alter the frequency of the shed vortexes. Recent TTR in deep sea are designed using the recommended standards from American Petroleum Institute (1998) for 1000-years hurricane condition. The environmental loading is usually developed from the structural response of the hull in which it is to be installed. The application of dry-trees concepts for production operations has been tested in different oil fields. Tremendous successes have been recorded over the years. However, due to the complexities associated with TLP and Spar in ultra-deep waters, various design concepts of semisubmersible platforms are currently under screening for possible replacement. Some of these concepts include:

- Paired Column Semisubmersible (PC-Semi)

- Extendable Draft Platform (EDP)

- Extended Semisubmersible (E-Semi) and Truss Semisubmersible (T-Semi)

- Aker Dry Tree Semisubmersible

- SBM FOURSTAR-Semisubmersible

- COTEC Jacket-Semisubmersible

Each of the above listed hull concepts comes with its own advantages. Amongst them, PC-Semi hull formation is the most realistic and generally accepted concept for this purpose as illustrated in Figure 6. This is attributed to the high payload it offers and the absence of any moveable part within the hull, as compare with the EDP, Esemi (Research Partnership to Secure Energy for America (RPSEA), 2014). More technical details on PC-Semi have therefore been reported in this paper.

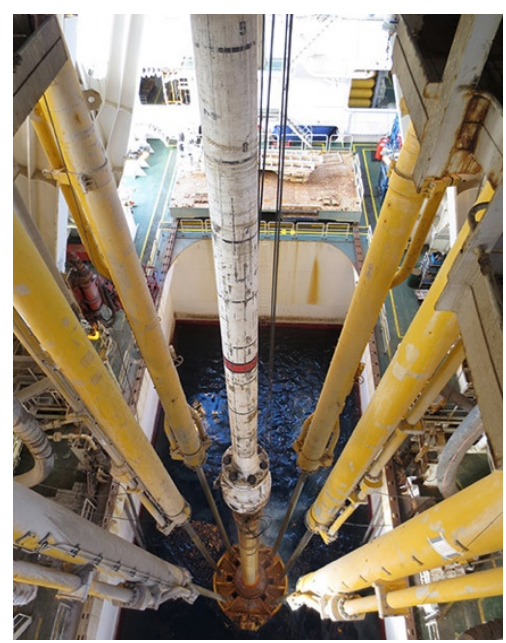

Figure 5. Example of top tension riser: Courtesy of JAMSTEC 

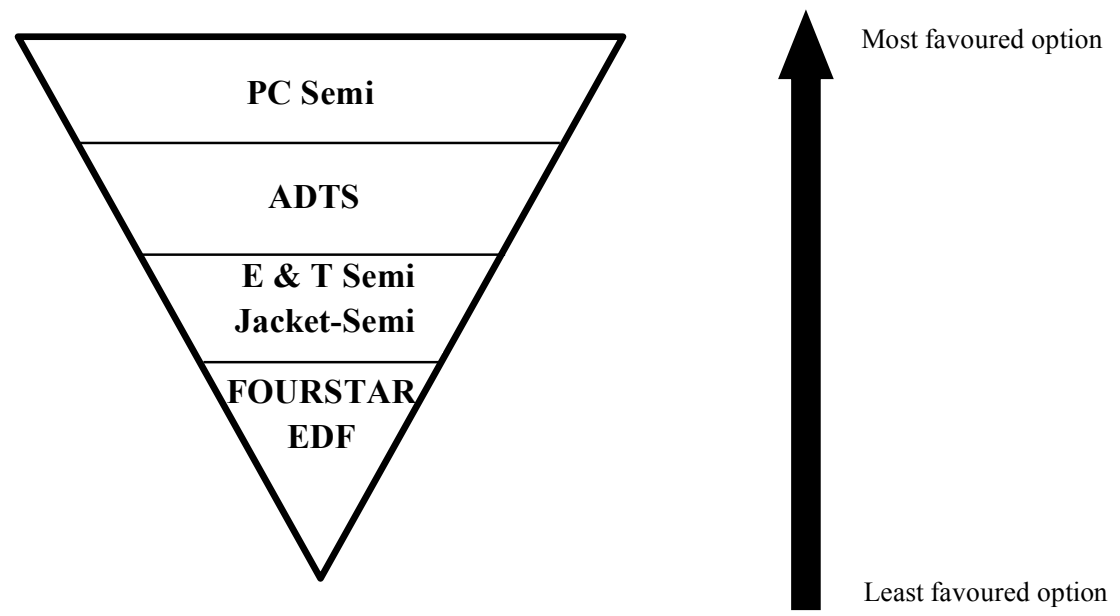

Figure 6. Comparisons of various Dry-Tree Semisubmerisbles

\subsection{The Extendable Draft Platform}

This structure was first designed in 2002 (Technip France), with the idea of combing the advantages of jackup rig and their deep draft semisubmersible as shown in Figure 7(a and b). The columns were designed to penetrate the topside, making it possible to control the size of the draft. With a plate-like shape pontoon design, it has reduced motion on its horizontal plane. Although its implementation was not very successful in the oil and gas industry, results from the experimental and numerical analyses showed that it had a high stability, coupled with its wide deck space that could accommodate both drilling and production units. Other researchers have made conscious attempts to continue developing this hull concept to make the design more feasible for fabrication / construction. Murray (2004) and Xu and Xu (2004) are some of the notable work that has been presented. Figure 7 shows an early sketch of the workability of this hull presented by Technip. The pontoon section acts as a heave reducing mechanism (heave plate), which helps in reducing the vertical motions during hydrodynamic wave and current loading.
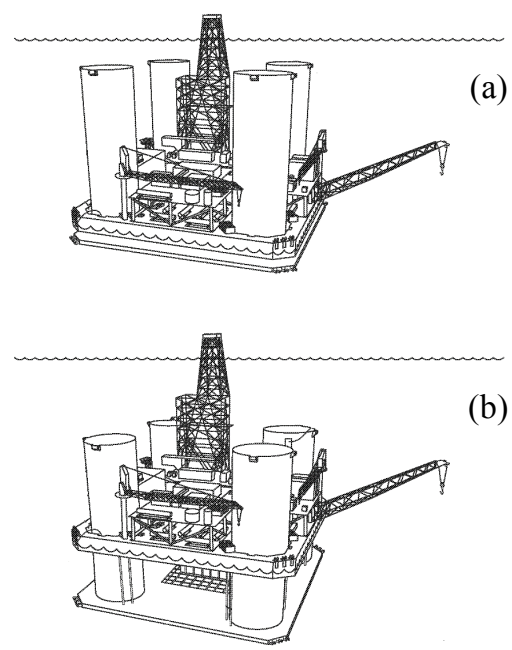

Figure 7. Examples of Extendable-Draft Semisubmersible. Courtesy: Technip France

The movable nature of the hull system makes it unattractive in ocean engineering. As a result, not much is known about the extendable draft platform, since its design has not been implemented in the industry.

5.2 E-Semi and T-Semi

*Correspondence author (j.ye2@lancaster.ac.uk) 
The extended and truss semis are two deep draft concepts that employ conventional heave plate method in reducing the motions in the vertical plane to allow compatibility with TTRs. These plate inclusions make their hull configuration more complex and increase the overall maintenance cost of the structures. The differences between them are the moveable single heave plate on E-Semi and the fixed truss set of plates on T-semi. Hao et al. (2013) described these concepts as a hybrid design, combining the advantages of a truss spar and a convention semisubmersible platform. Murray et al. (2008) studied the dynamics of E-Semi and T-Semi (Figure 8). The investigation was carried out for 100-years wave return period for post Katrina sea state in the Gulf of Mexico. Eight TTRs of total weight $4.5 \times 10^{5} \mathrm{Kg}$ were fitted on each of the hull. Their vertical motions were studied for each hull configuration. The results obtained for the vertical motion of the TTRs were observed to be less than $9 \mathrm{~m}$, which is the recommended standard for stroke limit of TTR. The development of E- and T-Semis can be attributed to FloaTEC.

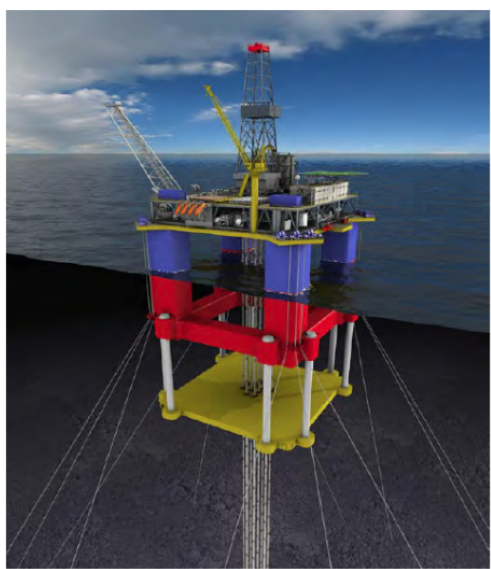

(a) E-semi

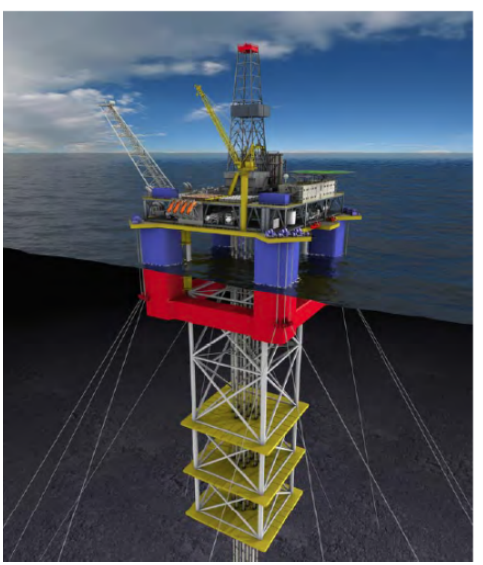

(b) T-semi

Figure 8. Examples of (a) Extended-Semi and (b) Truss-Semis: Courtesy FloaTEC

The idea of E- and T-Semis for dry-trees operations in deep waters was not successful in the industry. The reason for this is that the movable components on the hull of these structures make them less attractive to operators in this industry, as an ideal structure for deep and ultra-deep sea wells should have stable and stationary hull configuration

\subsection{Aker Deep Draft Concept (ADTS)}

The Aker Kvaerner deep draft is one of the practical ways of designing dry-trees semisubmersibles (DTS). This design was conceptualized with the intention of not altering the design of traditional semisubmersibles. The motion suppressing mechanism is achieved with the plate shape of the pontoon design placed beneath the columns. The plate acts as heave suppressing device. It functions with an array of tensioners, arranged in ram style which helps to support the top tension riser during operation (Yu, et al., 2013). The method was employed in the design and development of a Chevron operated structure called Blind Faith in 2007 (Offshore-technology, 2013).

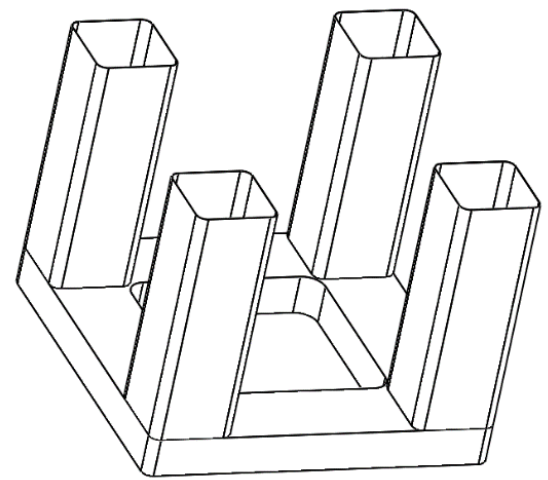

Figure 9. Illustration of a Aker deep-draft hull

The advantage the PC-Semi offers, when compared to Aker semisubmersibles, is the high payload integration. The eight columns arrangement of the PC-Semi displaces huge amount of water, in turn offers high amount of 
payload. Aker semisubmersibles do not offer this. An increase in the columns and pontoon sizes for more payloads will increase its motion, and this might eliminate its dry-trees compatibility.

\subsection{SBM FOURSTAR-Semi Concept}

SBM Atlantia has developed a dry-trees semisubmersible platform concept appropriate for deployment in nonhurricane/non-cyclonic environments worldwide (Williams et al., 2010). In the concept as shown in Figure 10, the columns are battered towards the geometric centre of the vessel. Platforms with these configurations are generally capable of supporting large payloads while maintaining stability during the various stages of integration, transportation and installation, and allow self-supported hull and mooring installation without the need for heavy lift vessels or supplemental buoyancies. The battered column geometry enables superior motion responses in the design environmental conditions. A laboratory investigation of the concept was conducted by assuming an application to a $2100 \mathrm{~m}$ depth offshore Brazil field. Hull displacement was 81,800 tons and total payload was 34,800 tons. Experimental and numerical results show that the maximum offsets over all sea states were within the design limits (Williams et al., 2010).

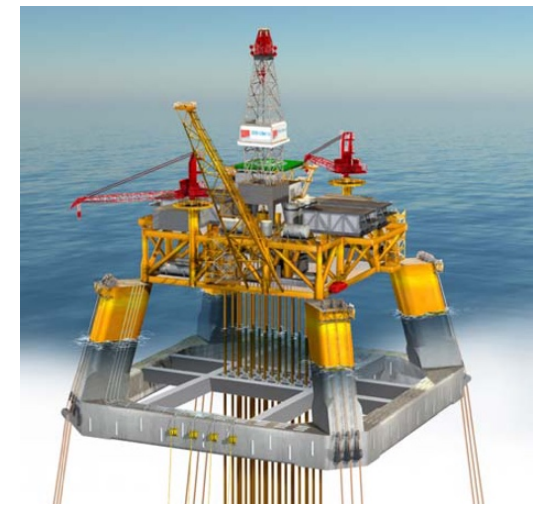

Figure 10. Illustration of FOURSTAR-Semi Concept: Courtesy SBM Atlantia (Williams et al., 2010)

\subsection{COTEC Jacket-Semi Concept}

A jacket-semi concept has been developed as an alternative option for dry trees applications (Qi et al., 2015). The proposed platform includes a deck, a supporting jacket frame attached to the bottom of the deck, and a hull structurally coupled to the jacket frame for stabilizing the offshore floating platform, as illustrated in Figure 11. Since the hull is not directly assembled with the deck for reducing the pry-squeeze load caused to the deck, design on its deep draft and column arrangement become significantly straightforward. Feasibility study was conducted by employing 100-year return environmental conditions from a $1500 \mathrm{~m}$ depth project in South China Sea. $4 \times 3$ mooring configuration and 9 TTRs were adopted. Well performed model tests and corresponding numerical simulation results showed significant motion behaviours in terms of both hull and its attachments (Qi et al., 2014). In addition, investigations on fabrication, transportation and installation have been carried out to verify the reliability and cost-effectiveness of the design (Qi et al., 2015). The concept may be applied to other types of semisubmersibles as presented in Table 1 and this section.

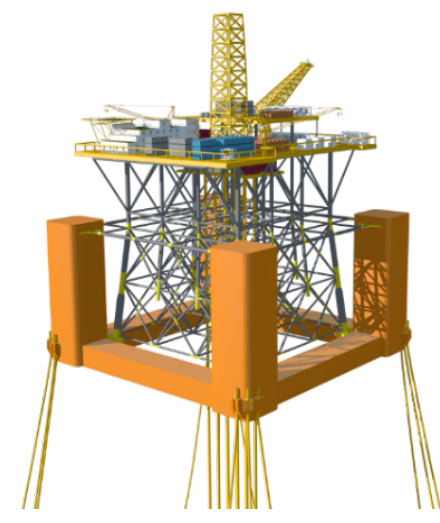

Figure 11 Illustration of Jacket-Semi concept: Courtesy COTEC Inc. (Qi et al., 2015) 


\subsection{Development of Paired Column Semisubmersible Hull}

In the oil and gas industry, there is a constant need to increase the safety level of deep water operations because the nature of damage caused by any form of failure can be catastrophic. BP oil spillage in the GOM in 2010 is an example of this. An effective way of improving safety is reducing subsea operations. Subsea operations do not allow direct access of wellheads and other drilling/production equipment, as they are done with Remotely Operated Underwater Vehicles (ROVs). For safety and cost effectiveness, top-deck well-heads are therefore more advantageous for production operations. TLP and Spar platforms are more favourable to semisubmersible hulls for design of production platforms in deep waters, because they are compatible with top deck well head installation. The conventional semisubmersibles, however, are not, despite they offer higher stability and more deck area. Spar and TLP are not as flexible as semisubmersible hulls. As discussed earlier, the problems associated with restoring stiffness of TLP and the complexities with the tethers make it less economical and unsafe for ultradeep operations (beyond 2000m sea depth). Spar platforms have very small working area, as they are suspended by a single column (SPAR). This acts as a disadvantage when selecting hulls for deep water production. Design engineers are forced to increase the size of the hull to create enough space for the equipment and staff needed for deep sea operation. The Perdido Spar is a good example of this. The development of a suitable structure that suits the requirement of production operation in ultra-deep sea regions therefore falls on semisubmersible hulls because of their wide surface area, stability, and installation convenience. Although semisubmersibles have excessive heave displacement and vortex induced vibration for deep-draft, reconfiguring its hull and deck compartment can help in reducing/eliminating the effect of these disadvantages. Paired Column Semisubmersibles were developed to serve this purpose. Designed in 2006 by Houston Offshore Engineering, the paired column semisubmersible platform (popularly known as PC-Semi) (Zou, 2012; Zou et al., 2013) is the most realistic concept of all the semisubmersibles designed with dry-trees installation. Unlike the hull concept postulated by Technip, the PCSemi, as illustrated in Figure 12, has a stationary stable hull, making it safer and more reliable for ultra-deep water. It has a significant reduction on the RAO heave curve as comparing to the conventional semisubmersible platforms, which makes it suitable for TTR installation. Although the massive size of the hull makes its construction less cost effective, its stability and reduced motion response makes it very viable for ultra-deep water drilling and production operations.

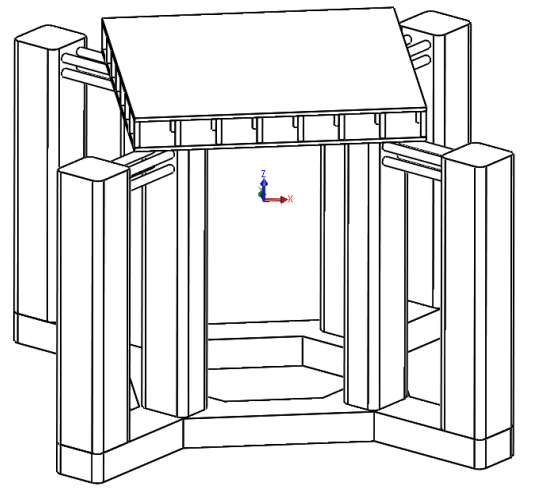

Figure 12 Model of a Paired Column Semisubmersible

Some experiments have been conducted to understand the VIM behaviour of this hull, and the results obtained were recorded in Zou et al. (2013) and Zou (2014). The experiments were developed for the same weather conditions, draft appendage, flow orientation and hull geometric parameters. Analysis was carried out for $0^{\circ}$ flow angle. Zou et al. (2013) presented VIM tests of a free floating PC-Semi hull for a scale of 1:160, using a tow speed range between $0.1 \mathrm{~m} / \mathrm{s}$ and $0.6 \mathrm{~m} / \mathrm{s}$. Investigation was carried out for two draft conditions, i.e., $50.3 \mathrm{~m}$ and $48.8 \mathrm{~m}$. Comparisons were also made between traditional four columns deep draft semisubmersibles and PC-Semi. VIM amplitudes were computed, and the reduced velocity was calculated in relation with vortex shedding amplitude. The characteristic length was measured as the diagonal distance of each outer column, which spanned to $19.4 \mathrm{~m}$. The relationship between the reduced velocity $\left(V_{R}\right)$ and the oscillating amplitude (Max A/D) was observed to be linear between $0^{\circ}$ and $45^{\circ}$. This linearity was experienced for reduced velocity greater than 3.5 . For $V_{R}$ range between 4 and 11, the reciprocating amplitude of the shed vortexes / the hull gradually reduced from $0^{\circ}$ to $45^{\circ}$. The maximum value for Max A/D was recorded as 0.4 . It is important to mention that between a reduced velocity range of 4.5 to 11 , there was no significant variation observed between the reciprocating amplitudes, i.e., for a specific flow angle, a change in the reduced velocity (natural frequency of the hull) does not cause any significant change in the reciprocating amplitude of the hull. This is a very useful parameter for motion characteristics of the vibrating tendencies of this hull system from vortex shedding. Similar $V_{R}$ was observed for the hull drag, but the 
relation it has with the flow angle was observed to be different. The maximum value of hull drag was recorded at $22.5^{\circ}$ flow angle. There was a gradual increase between $0^{\circ}$ and $22.5^{\circ}$ and a drastic decrease between $22.5^{\circ}$ and $45^{\circ}$. This irregularity of drag coefficient around the hull is relative to the surface area exposed to the incident flow. An experimental study in understanding the effect of hull appendage /draft size on the drag coefficient around a deep draft semisubmersible hull system was reported in Gonçalves et al. (2012b). In the report, results were documented for drag coefficient, which was observed to be relative to submerged hull area. The major contributor to this phenomenon is the inclusion of the pontoon section. Drag effect on multiple array of column presented in Lam, et al (2008), Zhou et al. (2011) and Han et al. (2013) do not necessarily show this phenomenon. The drag variation around the columns is basically subject to whether a specific column is buried in the wake formed from the flow separation from a leading column. Maximum drag from the summation of all columns is mostly recorded at $45^{\circ}$ flow angle. From this assessment, we can therefore speculate that the inclusion of the centralized pontoon section plays a significant role in the drag distribution around the hull of a typical PC-Semi. This unique behaviour has been investigated using CFD method in Kim et al. (2015) where it was stated that the pontoon section was observed to be responsible for one-third of the entire drag around this hull. The maximum value for hull drag coefficient was recorded between 1.1 and 1.2, at a reduced velocity of 5.57 .

Results were also recorded for a reduced draft size of $48.8 \mathrm{~m}$. The draft size was observed to have effect on the Max A/D, for a reduced velocity range of 3.6 and 8.8. Maximum values were recorded at the middle of the range. The drag effect for both draft sizes was more significant. The variation in the average value of the horizontal line graph for drag coefficient recorded for $53.34 \mathrm{~m}$ and $48.8 \mathrm{~m}$ are over $0.2 \mathrm{~m}$ apart. This is significant, considering the fact that the average value of drag coefficient of $53.3 \mathrm{~m}$ draft size, recorded at different reduced velocities, is 1.0 , while the average value recorded for $48.8 \mathrm{~m}$ draft size is 0.8 . From this, we can assume a $20 \%$ reduction in drag coefficient for a draft size reduction of $8.5 \%$ (53.34m to $48.8 \mathrm{~m})$. This is another useful parameter that might be required in controlling the wave forces acting on the hull during tow, installation or transportation. The extent of the columns and pontoon contributions to this reduction was not clearly defined in this experimental study. A recommendation for numerical study into the drag effect on eight arrays of columns (without the pontoon section) will be necessary to understand the contribution of the columns and pontoon section to this reduction. The parameters (drag and Max A/D) were also checked with conventional four columns arrangement for $0^{\circ}$ and $45^{\circ}$ and good agreements were recorded. A better understanding of how VIM effect on PC-Semi might be compared to VIM in conventional deep draft semisubmersible was recorded in Zou (2014). Comparisons were made between the results obtained in Zou et al. (2013) for PC-Semi and those of conventional deep-draft semisubmersibles. A comparison of Max A/D parameter was carried out for $0^{0}, 22.5^{\circ}$, and $45^{\circ}$. For the four columns deep draft system, square columns were used, with a draft size of $45.7 \mathrm{~m}$, characteristics length of $30.2 \mathrm{~m}$, column length of $21.3 \mathrm{~m}$ and a slender ratio of 1.5. The setup was developed in MARIN for a scale of 1:54. 16 mooring lines were incorporated into the system to study the effect of fatigue on this new hull system. For free floating condition, the same results were obtained as in Zou et al. (2013). This was a significant indication that scaling does not affect the reliability of the results from the VIM study of some ocean structures, such as PC-Semi. The mooring integration system was steel-polyester-steel. Details of the result obtained for mooring fatigue system can be found in the tests (Zou, 2014). DNV S-N curves and API T-N curves were used to test for the fatigue life of the lines. The mooring lines were observed to have a longer life span for PC-Semi when compared to conventional deep draft semisubmersibles, due to its reduced response amplitude.

\subsection{Offshore Wind Turbine Foundation}

Over the last 20 years, there has been a significant increase in generating energy from offshore wind farms, because of the high demand for renewable energy. Between 1993 and 2014, Global Wind Energy Council (GWEC) estimated the energy production from wind farms to be 5MW and 8045MW. This rapid increase was made possible by the introduction of bigger and more efficient wind turbines. As the size increases, the weight does. To maintain the required stability, the system requires bigger foundation. To resolve this complication, design engineers used semisubmersibles and TLPs, in place of the floating spar cylinders. The unfavourable conditions associated with TLP and water depth imply that engineers are left with the option of using semisubmersible hulls to suspend these gigantic wind turbines in deep waters. This is why there has been a high research attention in understanding the stability of semisubmersible hull in rough sea weather, subject to maximum wind turbine rotation. Zhang et al. (2013) studied the dynamic response of a three-column semisubmersible foundation system of a wind turbine in frequency and time domains. Their tripod semisubmersible was anchored with six mooring cables, two on each column, and the turbine was designed to sit in the middle, supported with a frame of triangular trusses. Results from their study showed that a higher stability was required from the foundation (semisubmersibles) to effectively reduce the turbine motion and optimize the energy extraction from the blade rotation. The wind load on the turbine was also observed to be influential in calculating the strength of the semisubmersible foundation system. A more recent study presented by Michailides et al. (2016) compared 
experimental and numerical results of the design described in Zhang et al. (2013) with the incorporation of three Wave Energy Converter (WEC) on each pontoon section of the tripod. The results for the motion response were presented in relation to the energy generated from these converters. Karimirad and Michailides (2015) recorded the dynamic response of a V-shaped semisubmersible foundation system for an offshore wind turbine. The results showed that, unlike Mobile Offshore Drilling Units (MODU) and Floating Production Systems (FPS), the motion of the system was greatly affected by the wind loads. This implies that the 'hydrostatic parameters' of the Vshaped semi has to be accurately selected to determine its functionality. The motion test for different cases for wave and wind loads suggested a possible application of this hull for wind turbine foundation. Other literatures and background for designing offshore wind turbine foundation systems can be found in Ishihara et al. (2007) and Jonkman (2007).

\subsection{Future Application: Luxury Cruise}

Deep-draft semisubmersibles are the future of ocean engineering, because of the level of stability they can offer from reconfiguration. In September of 2015, the Cable News Network (CNN) reported a documentary on a new form of luxury cruise, designed as a mini-island (CNN, 2015). The floating system was designed by Migaloo Private Submersible Yachts (see Figure 13). The hull of the floating mini island was built with a column stabilized semisubmersible. This hull will be required to function as a yacht or a cruise ship, with extremely high level of stability. The significant advantages it offered over the conventional cruise boats were the type and amount of deck support integration.

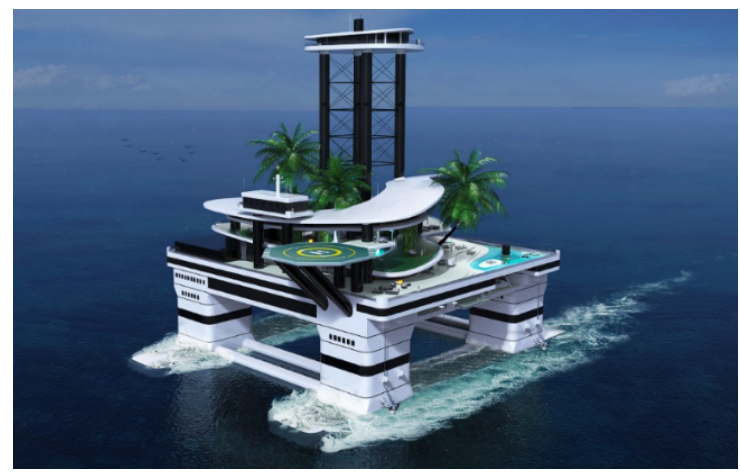

Figure 13 Semisubmersible Mini Island (CNN, 2015)

\subsection{Conclusion}

A detailed review into the origin and background of semisubmersible hull has been presented in this paper. The progress made so far in optimizing its functionalities / usefulness and increasing its application in ocean engineering was reviewed. A brief summary of some contributions made by industrial and academic researchers in improving its motion response was reported, and the techniques adopted for each invention were discussed. The rapid proliferation of deep draft semisubmersibles for deep water operations was discussed, and the challenges (such as vortex induced vibration) that have been recorded so far by operators were also highlighted. The present recommendations for circumventing some of these challenges were further discussed. A review into its structural attachments and degree of freedoms were included alongside its strength and dynamic behaviour during environmental loading. Finally, the applications of semisubmersibles in drilling and production operations were discussed, including the support systems for wind turbine foundation and luxury accommodation design.

It is evident from the review on the application of semisubmersibles for wind turbine foundation system and dry-trees compatibility that there is continuous need to develop offshore semisubmersible hull systems for deep water offshore applications, as they offer favourable payloads and reduced motion characteristics. Furthermore, there are concerns regarding the influence of wind loads and turbine rotation on the strength of the proposed semisubmersible hull. For dry-trees installations, the review on PC-Semis so far suggested a possible application to circumvent the demand for dry-trees in deep waters. As a result, there is a need for further research into its dynamic behaviour, alongside understanding its stress pattern from wave and wind loads. 


\section{Reference}

Akagi, S. and Ito, K. (1984) 'Optimal Design of Semisubmersible Form by Minimizing its Motion in Random Seas', Journal of Mechanisms, Transmissions, and Automation in Design. ASME, 106(1), pp. 23-30. Available at: http://dx.doi.org/10.1115/1.3258555.

Alexei, B. (2001) 'Oil-Services Firms Take a Bath on Deep- Water Drilling - Offshore Exploration Presents Higher Costs, Greater Technological Challenges', in, p. B.4.

American Bureau of Shipping (2004) Guide for Buckling and Ultimate Strength Assessment for Offshore Structures. Houston, Texas, USA.

American Bureau of Shipping (2015) Offshore Innovation: A Histroy of Offshore Development. Available at:

https://www.eagle.org/eagleExternalPortalWEB/ShowProperty/BEA Repository/References/Capability Brochures/OffshoreInnovationCp.

American Petroleum Institute (1997) 'API 2INT-MET:Interim Guidance on Hurricane Conditions in the Gulf of Mexico’.

American Petroleum Institute (1998) Recommended Practice 2RD:Design of Risers for Floating Production Systems (FPSs) and TensionLeg Platforms (TLPS). First. USA.

American Petroleum Institute (2008) Design of Flat Plat Structure. USA

Bai, Y. and Bai, Q. (2005) Subsea Pipelines and Risers, Elsevier Science. doi: 10.1016/B978-008044566-3.50023-3.

Bai, Z., Xiao, L., Kou, Y. and Yang, L. (2013) 'Research on vortex induced motion of a deep draft semisubmersible with four rectangular columns', in Proceedings of the 23rd International Offshore and Polar Engineering Conference.

Begnaud, E. E., Norton, C. V., Malcolm, B. and Friede \& Goldman, L. (2002) Dynamically positioned semi-submersible drilling vessel with slender horizontal braces. USA.

Bentley, C. R. and Koci, B. R. (2007) 'Drilling to the beds of the Greenland and Antarctic ice sheets: A review', Annals of glaciology, 47(1), pp. 1-9.

Bindingsbo, A. U. and Bjorset, A. (2002) 'Deep draft semisubmersible', in Proceedings of the 21st International Conference on Offshore Mechanics and Arctic Engineering, pp. 651-659. doi: 10.1115/OMAE2002-28369.

Chakrabarti, S. (2005) Handbook of Offshore Engineering (2-volume set). 1st edn. Elsevier Science. Available at: https://www.elsevier.com/books/handbook-of-offshore-engineering-2-volume-set/chakrabarti/978-0-08-044381-2.

Chakrabarti, S., Barnett, J., Kanchi, H., Mehta, A. and Yim, J. (2007) 'Design analysis of a truss pontoon semi-submersible concept in deep water', Ocean Engineering, 34(3-4), pp. 621-629. doi: 10.1016/j.oceaneng.2006.03.012.

CNN (2015) 'Forget the boat, here's the island you can sail'. Available at: http://edition.cnn.com/2015/09/24/sport/gallery/migaloosubmersible-yacht-floating-island/.

Det Norske Veritas (2011) DNV-OS-C201:Structural Design of Offshore Units (WSD Method).

Det Norske Veritas (2012) DNV-OS-C104:Structural Design of Self-Elevating Units (LRFD Method).

Det Norske Veritas (1987) DNV-CN-31: Strenght Analysis of Min Structures of Column Stabilized Units (Semisubmersible Platforms)

Diamond Offshore (2016) Deepwater Rigs: Ocean Apex \& amp; Ocean Onyx. Available at: http://www.diamondoffshore.com/video-360degree-flyaround-of-the-ocean-apex.

Ding, Y. and Soester, W. L. (2011) 'Truss semi-submersible offshore floating structure'. USA. Available at:

http://www.google.es/patents/US7871222.

DNV GL (2015) DNVGL-CG-0128: Buckling. Oct. 2015. Available at: https://rules.dnvgl.com/docs/pdf/DNVGL/CG/2015-10/DNVGLCG-0128.pdf.

Duan, M., Wang, Y., Yue, Z., Estefen, S. and Yang, X. (2010) 'Dynamics of risers for earthquake resistant designs', Petroleum Science, 7(2), pp. 273-282. doi: 10.1007/s12182-010-0033-9.

Erdbrink, R. J. (1990) ‘Semi-submersible crane vessel’. USA.

Gonçalves, R., Rosetti, G., Fujarra, A., Nishimoto, K. and Oliveira, A. (2012a) 'Vortex-induced yaw motion (VIY) of a large-volume semisubmersible platform', in Proceedings of the 22nd International Offshore and Polar Engineering Conference. Rhodes, Greece.

Gonçalves, R. T., Rosetti, G. F., Fujarra, A. L. and Oliveira, A. C. (2012b) 'Experimental study on vortex-induced motions of a semisubmersible platform with four square columns, Part I: Effects of current incidence angle and hull appendages', Ocean Engineering, 54, pp. 150-169. doi: 10.1016/j.oceaneng.2012.06.032.

Gonçalves, R. T., Rosetti, G. F., Fujarra, A. L. and Oliveira, A. C. (2012c) 'Experimental study on vortex-induced motions of a semisubmersible platform with four square columns, Part II: Effects of surface waves, external damping and draft condition', Ocean Engineering, 62, pp. 10-24. doi: 10.1016/j.oceaneng.2013.01.019. 
Halkyard, J. (2005) 'Chapter 7-Floating Offshore Platform Design', in Handbook of Offshore Engineering. Elsevier Ltd., pp. 419-661. doi: 10.1016/B978-008044381-2.50010-2.

Han, Z., Zhou, D., Gui, X. and Tu, J. (2013) 'Numerical study of flow past four square-arranged cylinders using spectral element method', Computers \& Fluids, 84, pp. 100-112. doi: 10.1016/j.compfluid.2013.05.008.

Hong, Y., Choi, Y., Lee, Y. and Kim, Y. (2008) 'Vortex-Induced Motion of a Deep-Draft Semi-Submersible in Current and Waves', in Proceedings of the 18th International Conference On Offshore Mechanics and Arctic Engineering. Canada.

Hussain, A., Nah, E., Fu, R. and Gupta, A. (2009) 'Motion comparison between a conventional deep draft semi-submersible and a dry tree semi-submersible', in Proceedings of the 28th International Conference on Ocean, Offshore and Arctic Engineering. Hawaii, USA, pp. 785-792. doi: 10.1115/OMAE2009-80006.

Ishihara, T., Phuc, P. Van, Sukegawa, H. and Shimada, K. (2007) 'A study on the dynamic response of a semi-submersible floating offshore wind turbine system Part 1: A water tank test', in Proceedings of the 12th International Conference on Wind Engineering, pp. 4-7. Available at: http://windeng.t.u-tokyo.ac.jp/ishihara/paper/2007-3.pdf.

Jonkman, J. M. (2007) Dynamics modeling and loads analysis of an offshore floating wind turbine, National Renewable Energy Laboratory. Report. Available at: http://www.nrel.gov/docs/fy08osti/41958.pdf.

Jordan, M. A. and Beltran-Aguedo, R. (2004) 'Nonlinear identification of mooring lines in dynamic operation of floating structures', Ocean Engineering, 31(3-4), pp. 455-482. doi: 10.1016/S0029-8018(03)00122-7.

Kaewunruen, S., Chiravatchradej, J. and Chucheepsakul, S. (2005) 'Nonlinear free vibrations of marine risers/pipes transporting fluid', Ocean Engineering, 32(3-4), pp. 417-440. doi: 10.1016/j.oceaneng.2004.07.007.

Karimirad, M. and Michailides, C. (2015) 'V-shaped semisubmersible offshore wind turbine: An alternative concept for offshore wind technology’, Renewable Energy, 83, pp. 126-143. doi: 10.1016/j.renene.2015.04.033.

Kashiwagi, M. (2000) 'Hydrodynamic interactions amoung a great number of columns supporting a very large flexible structure', Journal of Fluids and Structures, 14(7), pp. 1013-1034. doi: 10.1006/jfls.2000.0306.

Kim, S. J., Spernjak, D., Holmes, S., Vinayan, V. A. and Antony, A. (2015) 'Vortex-induced motion of floating structures: CFD sensitivity considerations of turbulence model and mesh refinement', in Proceedings of the 34th International Conference on Ocean, Offshore and Arctic Engineering. St. John's, Newfoundland, Canada, p. V002T08A057. doi: 10.1115/OMAE2015-42221.

Knox, D., Smith, C. and Sedlmayer, A. (2015) Revolutionary Design for Semisubmersible Hull Catamaran. OSSeas Con.

Kyoung, J. H., Hong, S. Y., Kim, J. W. and Bai, K. J. (2005) 'Finite-element computation of wave impact load due to a violent sloshing', Ocean Engineering, 32(17-18), pp. 2020-2039. doi: 10.1016/j.oceaneng.2005.04.003.

Lam, K., Gong, W. Q. and So, R. M. C. (2008) 'Numerical simulation of cross-flow around four cylinders in an in-line square configuration', Journal of Fluid Mechanics and Structures, 24(1), pp. 34-57. doi: 10.1016/j.jfluidstructs.2007.06.003.

Leffler, W. L., Pattarozzi, R. and Sterling, G. (2003) Deepwater petroleum exploration \& production: a nontechnical guide (Deepwater petroleum exploration and production). Tulsa, Okla: Pennwell.

Lloyd's, R. (2011) Drilling in Extreme Enviroment: Challenges and implications for the energy insurance industry. Available at: https://www.lloyds.com/ /media/lloyds/reports/emerging risk reports/lloyds drilling in extreme environments final3.pdf.

Makinson, K., Pearce, D., Hodgson, D. A., Bentley, M. J., Smith, A. M., Tranter, M., Rose, M., Ross, N., Mowlem, M., Parnell, J. and Siegert, M. J. (2016) 'Clean subglacial access: prospects for future deep hot-water drilling', Philosophical Transactions of the Royal Society A: Mathematical, Physical and Engineering Sciences, 374(2059), p. 20140304. doi: 10.1098/rsta.2014.0304.

Malcolm, B. and Dixon, P. (2001) 'Column-stabilized offshore vessel'. USA. Available at:

http://appft1.uspto.gov/netacgi/nphParser?Sect1=PTO1 $\{\&\}$ Sect2=HITOFF $\{\&\}$ d=PG01 $\{\&\}$ p=1 $\{\&\} \mathrm{u}=/$ netahtml/PTO/srchnum.html $\{\&\} \mathrm{r}=1$ $\{\&\} \mathrm{f}=\mathrm{G}\{\&\} 1=50\{\&\} \mathrm{s} 1=20020090270$. PGNR.

Matos, V. L. F., Simos, A. N. and Sphaier, S. H. (2011) 'Second-order resonant heave, roll and pitch motions of a deep-draft semisubmersible: Theoretical and experimental results', Ocean Engineering, 38(17-18), pp. 2227-2243. doi: 10.1016/j.oceaneng.2011.10.005.

Mavrakos, S. A., Papazoglou, V. J., Triantafyllou, M. S. and Hatjigeorgiou, J. (1996) ‘Deep water mooring dynamics', Marine Structures, 9(2), pp. 181-209. doi: 10.1016/0951-8339(94)00019-O.

Michailides, C., Gao, Z. and Moan, T. (2016) 'Experimental and numerical study of the response of the offshore combined wind/wave energy concept SFC in extreme environmental conditions', Marine Structures, 50, pp. 35-54. doi: 10.1016/j.marstruc.2016.06.005.

Murray, J. (2004) ‘Extendable draft platform with buoyancy column strakes’. USA. Available at: http://www.google.com/patents/US7467912.

Murray, J. J., Yang, C. K., Chen, C. and Nah, E. (2008) 'Two dry tree semisubmersible designs for ultra deep water Post-Katrina Gulf of Maxico', in Proceedings of the 27th International Conference on Offshore Mechanics and Arctic Engineering, pp. 433-440. doi: 10.1115/OMAE2008-57462. 
Newman, J. N. (1994) 'Wave effects on deformable bodies', Applied Ocean Research, 16(1), pp. 47-59. doi: 10.1016/0141-1187(94)900132 .

Odijie, A.C. and Ye, J.Q., (2015). Effect of vortex induced vibration on a paired-column semisubmersible platform. International Journal of Structural Stability and Dynamics, 15(08), p.1540019.

Odijie, A.C., Quayle, S. and Ye, J.Q., (2017). Wave induced stress profile on a paired column semisubmersible hull formation for column reinforcement. Engineering Structures, 143, pp.77-90.

Offshore-Mag. (2012) Dry trees offer alternative for deepwater development. Available at: http://www.offshore-

mag.com/articles/print/volume-72/issue-6/engineering-construction-installation/dry-trees-offer-alternative-for-deepwater-development-.html (Accessed: 26 May 2017).

Offshore-technology (2013) Blind Faith Subsea Development, United States of America. Available at: http://www.offshoretechnology.com/projects/blindfaith/ (Accessed: 26 May 2017).

Priest, T. (2007) 'Extraction not creation: The history of offshore petroleum in the gulf of Mexico', Enterprise \& Society, 8(2), pp. $227-267$. doi: $10.1093 / \mathrm{es} / \mathrm{khm} 027$.

Qi, X., Lv, G., Li, H., Li, Y. and Luo, Y. (2015) 'Jacket Dry Tree Semi-submersible Platform with TTR System', in Proceedings of 25th International Ocean and Polar Engineering Conference, pp. 1591-1597.

Qi, X., Lv, G., Luo, Y., Zhu, W. and Zhang, Y. (2014) 'Model Test and Simulation of a New Concept of Dry Tree Semi-Submersible', in Proceedings of the 24th International Ocean and Polar Engineering Conference, pp. 985-992.

Research Partnership to Secure Energy for America (RPSEA) (2014) Ultra-deepwater dry tree system for drilling and production in the Gulf of Mexico. Report. Available at: http://www.rpsea.org/media/files/project/38e0afee/10121-4405-02-FR-

UDW_Dry_Tree_System_Drilling_Production_GOM-12-30-14_P.pdf.

Rijken, O., Schuurmans, S. and Leverette, S. (2011) 'Experimental investigations into the influences of SCRs and appurtenances on deepdraft semisubmersible vortex induced motion response', in Proceedings of the 30th International Conference on Ocean, Offshore and Arctic Engineering, pp. 269-279. Available at: http://dx.doi.org/10.1115/OMAE2011-49365.

Sarkar, A. and Taylor, R. E. (2002) 'Dynamics of mooring cables in random seas', Journal of Fluids and Structures, 16(2), pp. $193-212$. doi: $10.1006 /$ jfls.2001.0415.

Sharma, R., Kim, T. W., Sha, O. P. and Misra, S. C. (2010) 'Issues in offshore platform research - part 1: Semi-submersibles', International Journal of Naval Architecture and Ocean Engineering, 2(3), pp. 155-170. doi: 10.3744/JNAOE.2010.2.3.155.

Srinivasan, N., 2004. Column-stabilized floating structures with truss pontoons. U.S. Patent 6,761,124.

Sundaravadivelu, R., Kanotra, R. and Srinivasan, N. (2014) 'Transportation Analysis of Dry Tree Semisubmersible', International Journal of Ocean and Climate Systems, 5(2), pp. 105-116. doi: 10.1260/1759-3131.5.2.105.

Tan, J. H., Kiprawi, F., Kyoung, J., Sullivan, J. F. O. and A, N. J. (2016) 'Dry Tree Semisubmersible for Cost-Effective Deepwater Development', in Proceedings of the Offshore Technology Conference Asia. Malaysia.

William, J., Bennett, T. and Laborde, A. J. (2001) 'Deep draft semi-submersible offshore structure'. USA. Available at: http://www.google.co.uk/patents/US6190089.

Williams, N., Leverette, S., Bian, S., Large, S., Cao, P., Leverette, N., Bian, S., Large, S. and Cao, P. (2010) 'FourStar Dry-Tree Semisubmersible Development', in Proceedings of the 29th International Conference on Ocean, Offshore and Arctic Engineering, pp. 287294.

Wilson, J. F. (1984) Dynamics of offshore structures. New York: Wiley.

Wu, S., Murray, J. J. and Virk, G. S. (1997) 'The motions and internal forces of a moored semi-submersible in regular waves', Ocean Engineering, 24(7), pp. 593-603. doi: 10.1016/S0029-8018(96)00015-7.

Xu, J. and Haddara, M. R. (2001) 'Estimation of wave-induced ship hull bending moment from ship motion measurements', Marine Structures, 14(6), pp. 593-610. doi: 10.1016/S0951-8339(01)00010-7.

$\mathrm{Xu}, \mathrm{Q}$. (2011) 'A new semisubmersible design for improved heave motion, Vortex-Induced Motion and quayside stability', in Proceedings of the 30th International Conference on Ocean, Offshore and Arctic Engineering, pp. 95-103. doi: 10.1115/OMAE2011-49118.

Xu, Q. and Xu, L. (2004) 'An Introduction to Extendable Draft Platform (EDP)', in Proceedings of the 14th International Offshore and Polar Engineering Conference. Toulon, France, pp. 546-550.

Yu, H., Chen, Y. and Cui, Y. (2013) 'State of the art dry tree semi technologies', Engineering Sciences, 11(4), pp. 92-96. doi: 10.3969/j.issn.1672-4178.2013.04.014.

Zhang, R., Tang, Y., Hu, J., Ruan, S. and Chen, C. (2013) 'Dynamic response in frequency and time domains of a floating foundation for offshore wind turbines', Ocean Engineering, 60, pp. 115-123. doi: 10.1016/j.oceaneng.2012.12.015. 
Zhou, T., Razali, S. F. M., Hao, Z. and Cheng, L. (2011) 'On the study of vortex-induced vibration of a cylinder with helical strakes', Journal of Fluids and Structures, 27(7), pp. 903-917. doi: 10.1016/j.jfluidstructs.2011.04.014.

Zhu, H., Ou, J. and Zhai, G., 2012. Conceptual design of a deep draft semi-submersible platform with a moveable heave-plate. Journal of Ocean University of China (English Edition), 11(1), pp.7-12.

Zou, J. (2012) ‘Dual column semisubmersible for offshore application’. USA.

Zou, J. (2014) 'VIM Response of a Dry Tree Paired-Column Semisubmersibles Platform and its Effects on Mooring Fatigue', in 19th Offshore Symposium. Society of Naval Architects and Marine Engineers Texas Section.

Zou, J., Poll, P., Roddier, D., Tom, N. and Peiffer, A. (2013) 'VIM testing of a paired column semi submersible', in Proceedings of the 32nd International Conference on Ocean Offshore and Arctic Engineering. Nantes, France, p. V007T08A001. doi: 10.1115/OMAE2013-10001. 